\title{
Production, Distribution, and Trade: General Equilibrium Models with One Single Cobb-Douglas Parameter
}

\author{
Hidetaka Kawano1, Hiroshi Ohta², Bjarne S. Jensen³, Amy R. Hwang4 \\ ${ }^{1}$ School of Management and Economics, Aomori Public University, Aomori, Japan \\ ${ }^{2}$ School of International Politics, Economics \& Communication, Aoyama Gakuin University, Tokyo, Japan \\ ${ }^{3}$ Department of Environmental and Business Economics, University of Southern Denmark, Esbjerg, Denmark \\ ${ }^{4}$ Department of International Trade, Private Chinese Cultural University, Taiwan \\ Email: kawano@b.nebuta.ac.jp, ohta@sipeb.aoyama.ac.jp, bsj@sam.sdu.dk,hrm@faculty.pccu.edu.tw
}

How to cite this paper: Kawano, H., Ohta, H., Jensen, B.S. and Hwang, A.R. (2017) Production, Distribution, and Trade: General Equilibrium Models with One Single Cobb-Douglas Parameter. Modern Econo$m y$, 8, 970-993.

https://doi.org/10.4236/me.2017.87068

Received: April 18, 2017

Accepted: July 25, 2017

Published: July 28, 2017

Copyright (c) 2017 by authors and Scientific Research Publishing Inc. This work is licensed under the Creative Commons Attribution International License (CC BY 4.0).

http://creativecommons.org/licenses/by/4.0/

\begin{abstract}
We present simple general equilibrium models of resource allocation, factor income distribution, and trade among nations that are technologically identical, but different in tastes. Under conditions of autarky, this paper highlights the importance of "tastes" that determine the intra-national factor shares of returns to productive factors. We demonstrate how a stronger taste for specified factor-intensive goods leads to higher returns to factors intensively used. Trade, in our model, however, erases both intra-national and inter-national factor income inequalities caused by taste differences. Trade, therefore, is no good news to those factors and income groups benefitting from autarky. Free trade therefore is a difficult proposal not only in practice, but also in theory.
\end{abstract}

\section{Keywords}

General Equilibrium, Production, Factor Allocation, Income Distribution, International Trade, One Single Cobb-Douglas Parameter

\section{Introduction}

Main determinants of international trade are known in the literature to include differences in the methods of production (Ricardo), factor endowments (HeckscherOhlin), and tastes (or demand patterns a la Linder). While the study of tastes as a determinant of international trade has attracted little attention, we feel that further analysis is warranted. According to Jagdish Bhagwati [[1], pp. 27-29], Linder's central thesis is that the higher the volume of trade will be, the greater the similarity is in the demand patterns of the pair of trading countries (in 
Linder [[2], pp. 94-95] $\left.]^{1}\right)$.

Among these three different models the third one is hitherto least known, but not least important. Noting this apparent discrepancy, this paper attempts to narrow it by focusing on taste differences (rather than the similarities that Linder stressed) between otherwise identical trade partners, endowed with both identical technologies and identical sets of productive factors ${ }^{2}$. Expanding on Linder's work, we propose to move beyond the focus on similarities in taste, and examine how differences in taste affect international trade. Similar to Linder we will assume that the trade partners are otherwise identical, endowed with both identical technologies and identical sets of productive factors.

Moreover, this paper is also motivated by a beauty of simplicity to present our models of production, distribution, and trade. Proposed accordingly are general equilibrium (GE) models with two factor inputs, two outputs, and two nations. The two factors of production are allocated to two sectors to produce two kinds of goods under alternative conditions of autarky and free trade. Proposed models are therefore referred to as the $2 \times 2 \times 2$ GE models. The simple models are moreover made even simpler by only one CD (Cobb-Douglas) parameter to represent both intra-national differences in technologies and international differences in tastes. Nevertheless, the models are analytically solvable for all the assumed endogenous variables explicitly in terms of the assumed one single parameter.

Our single parameter modeling makes, without much loss of generality, the rich content of GE theory, such as the Stolper-Samuelson, readily available to the general reader as well as specialists in the field.

Our purpose therefore is twofold: 1) to present the simplest possible GE model of production, and resource allocation (pursuant to Ohta [10] directly, also to Jensen [11] indirectly); and 2) to reveal the bitter maxim of the StolperSamuelson theorem and the related proposal to "bribe" by Stolper and Samuelson [[12], p.73] for free trade ${ }^{3}$.

The original Walras GE model has long remained almost forlorn due to its gigantic structure sometimes referred to as a huge "empty box". We attempt at

${ }^{1}$ From the empirical standpoint, Armington [3] may also deserve mention, even more than Linder perhaps, for considering taste differences as important ingredients of trade theory, but as an anonymous referee points out its basic assumptions are "quite different" from our present model below. ${ }^{2}$ Bhagwati [[4], p. 46], in describing the world economy towards the end of the last century, refers to "kaleidoscopic" comparative advantage. Due to globalized "fierce competition", argues Bhagwati, "slight shifts in costs" can easily shift "comparative advantage", owing to modern effective communication and large bulk transportation. Therefore, the traditional supply side arguments of Ricardo and Heckscher-Ohlin predicated upon static and stable comparative advantage may no longer speak for themselves. In addition, it is also well known from many empirical studies starting from Leontief's seminal work [5], e.g., Trefler [6] that the Leontief paradox does exist. Focusing on taste differences, therefore, on the demand side of the theoretical argument may now deserve increasing attention. Along these lines recent contributions of particular interest, if not directly related to the present inquiry, include the discussions of optimal trans-Pacific trade barrier by Hübler [7], tourism to international trade by Santana-Gallego et al. [8], and the so-called product sophistication relevant to the stability of international trade by Córcoles et al. [9] among many others.

${ }^{3}$ In a nutshell we present both what Kemp [13] refers to as the "WADM model" of general equilibrium and the Stolper-Samuelson theory of trade. [Here WADM stands for Walras [14], Arrow and Debreu [15], and McKenzie [16]]. 
making the huge complex model as simple as possible so as to reveal the original importance of the Stolper-Samuelson theory ${ }^{4}$.

In what follows, Section 2 sets forth the formal mathematical system of equations along with the underlying assumptions to represent our simple $2 \times 2$ GE model without trade. Section 3 in turn sets forth a $2 \times 2 \times 2$ GE model of trade between two technologically identical nations that, however, have different national tastes. Section 4 discusses the GE solutions (with diagrams) for the autarky economies and the two free trading economies. Section 5 concludes. Figure 1 is produced in Latex. All the other computer generated Figures 2-7 are programmed in C-language and executed on the GCC version 4.0.1 compiler (Apple Computer, Inc.), and produced in Latex. The verified reliability of the simulation results in double precision (1.0e-15).

\section{The Closed $2 \times 2$ Economies}

\subsection{Assumptions}

We begin with an autarky model predicated on the following assumptions:

(A1-1) A country produces two final homogeneous goods: bananas $B$ and nuts $N$.

(A1-2) The country is endowed with two primary factors of production: capital $K$ (owned by capitalists) and labor $L$ (owned by workers).

(A1-3) The total factor endowments are normalized to unity: $\bar{L}=\bar{K}=1$.

(A1-4) The sector production functions are of CD technologies, such that in the sector producing $B$, the output elasticity of labor is $\alpha$, and that of capital is $(1-\alpha)$, whereas in the sector producing $N$, the output elasticity of labor is $(1-\alpha)$, and that of capital is $\alpha$.

(A1-5) Consumers (workers and capitalists) in the same country have identical tastes, defined by the same $\mathrm{CD}$ utility function, such that in one country, the parameter $\alpha$ is the utility elasticity of $\operatorname{good} N$, and $(1-\alpha)$ that of $\operatorname{good} B$; in the other country, these utility parameters are reversed.

Pursuant to these assumptions we now present our simplest possible models in what follows.

\subsection{The $2 \times 2$ Autarky Economies-1 CD Parameter Model}

Let us begin by describing a country, say, the Banana Country, which is producing two kinds of goods, bananas $B$ and nuts $N$. Their production functions are specifiable subject to Assumption (A1-4) as:

$$
B=g\left(L_{B}, K_{B}\right)=L_{B}^{\alpha} K_{B}^{1-\alpha}
$$

\footnotetext{
${ }^{4} \mathrm{~A}$ similar phrase "Of Empty Economic Boxes" in Clapham [17] refers to such general verbal concepts as marginal, diminishing returns, returns to scale, etc. These abstract concepts appeared hard indeed to be applied to real world analysis until Cobb and Douglas [18] first proposed an empirically testable production function applied to US Manufacturing. While following along this line by using the parametric $\mathrm{CD}$ forms extensively, we also make the size of the huge box the smallest possible for analytical simplicity. Cf. Fullerton and Ta [19] for a similar treatment of general equilibrium analysis (of tax incidence rather than the present interest of trade incidence) predicated upon the specific Cobb-Douglass production functions.
} 


$$
N=f\left(L_{N}, K_{N}\right)=L_{N}^{1-\alpha} K_{N}^{\alpha}
$$

where $B(=g()$.$) and N(=f()$.$) are specific \mathrm{CD}$ functions of capital $K_{i}$ and labor $L_{i}(i=B, N)$ used in the subscripted sectors, $B$ and $N$, respectively, the superscript $\alpha$ above represents "output elasticity" of capital in the $N$ sector and also "output elasticity" of labor in the $B$ sector. This is a deliberate contrivance (assumption) to differentiate the two sectors' methods of production by a single parameter $\alpha$.

The contrivance is deliberate in the sense that it is intended simply, yet generally, to derive the so-called contract curve CC in the familiar Edgeworth (endowment) box as a rectangular hyperbola in Allen [20] from a couple of Cobb-Douglas functions with distinct CD parameters $\alpha$ and $\beta$. Our present model with one parameter may appear to contradict the more general twoparameter outcome, but it does not. In fact, the present single parameter is contrived to represent two distinct $\mathrm{CD}$ parameters $\alpha$ and $\beta$, which is required, however, $\beta=1-\alpha^{5}$.

Utility functions of workers and of capitalists are defined, by Assumption (A1-5) above, as:

$$
\begin{aligned}
& U_{K}\left(B_{K}, N_{K}\right)=B_{K}^{1-\alpha} N_{K}^{\alpha} \\
& U_{L}\left(B_{L}, N_{L}\right)=B_{L}^{1-\alpha} N_{L}^{\alpha}
\end{aligned}
$$

where $U()$.$s on the left hand side are identical functions of B$ and $N$ consumed by the factor suppliers $K$ (capitalists) and $L$ (workers) having the same tastes. It is to be noted here that the same parameter $\alpha$ used to represent the production technology above in (1) and (2) is once again used to represent the consumers' utility functions (3) and (4).

These assumptions lead to the relevant optimization conditions subject to the budget constraints to follow below.

Consumptive Optimum: Equi-marginal utility MU per Dollar

$$
\begin{aligned}
& \frac{(1-\alpha)\left(\frac{N_{K}}{B_{K}}\right)^{\alpha}}{p_{B}}=\frac{\alpha\left(\frac{B_{K}}{N_{K}}\right)^{1-\alpha}}{p_{N}} \\
& \frac{(1-\alpha)\left(\frac{N_{L}}{B_{L}}\right)^{\alpha}}{p_{B}}=\frac{\alpha\left(\frac{B_{L}}{N_{L}}\right)^{1-\alpha}}{p_{N}}
\end{aligned}
$$

where the left hand side numerators are the factor provider $K(L)$ 's $\mathrm{MU}$ of banana $B$, the right hand sides are the corresponding MU of nuts $N$, and $p_{i}$ $(i=B, N)$ is the price of $i$ th good.

Individual Budget Constraints:

$$
r=p_{B} B_{K}+p_{N} N_{K}
$$

${ }^{5}$ The CC concavity thus contrived may be interpreted as a proxy for the extent of the differences in the "methods of production" in Stolper and Samuelson [12]. This is because the more concave (or convex) the CC, the more different the methods of production are, in terms of relative factor intensities. 


$$
w=p_{B} B_{L}+p_{N} N_{L}
$$

where $r$ is rental rate on capital (capitalists' income), $W$ wage rate (workers' income), $B_{i}$ bananas consumed, and $N_{i}$ nuts consumed, respectively, by factor owners of $K$ and $L$.

Related to the consumptive optimum are the productive/allocative optimum conditions, followed in turn by the market equilibrium conditions that must follow consecutively below. Thus,

Productive/Allocative Optimum (Equi-Marginal Rate of Technical Substitution, MRTS):

$$
\begin{aligned}
& \frac{w}{r}\left(=\frac{f_{L}}{f_{K}}\right)=\frac{1-\alpha}{\alpha} \frac{K_{N}}{L_{N}} \\
& \frac{w}{r}\left(=\frac{g_{L}}{g_{K}}\right)=\frac{\alpha}{1-\alpha} \frac{K_{B}}{L_{B}}
\end{aligned}
$$

where the left-hand sides of equations above represent the relative wage rate to rental rate $w / r$ and the right-hand sides the relative marginal product of factors $\left(=M P_{L} / M P_{K}\right)$ in the sector $i \quad(=B, N)$, respectively. Note that while the left-hand sides, $w / r$, are identical, the right-hand sides are defined as distinctively different functions of capital/labor ratio $K_{i} / L_{i}$ in sector $i$ $(=B, N)$.

Factor market equilibrium:

$$
\begin{aligned}
K_{B}+K_{N} & =1 \\
L_{B}+L_{N} & =1
\end{aligned}
$$

where total factor supplies (endowments), respectively, of $\bar{K}(=1)$ and $\bar{L}(=1)$, are required to be demanded by (allocated to) two sectors $B$ and $N$, respectively.

Product market equilibrium:

$$
\begin{gathered}
B=B_{K}+B_{L} \\
N=N_{K}+N_{L}
\end{gathered}
$$

where $B$ and $N$ supplied are to be demanded, respectively, by factors $K$ and $L$ in respective sectors.

Finally required for general equilibrium to be reached are the following conditions for income distribution.

Factor Income distribution (Factor Cost):

$$
\begin{gathered}
p_{B} B=w L_{B}+r K_{B} \\
p_{N} N=w L_{N}+r K_{N}
\end{gathered}
$$

where the left-hand sides are value outputs (revenues) of $B$ and $N$, respectively, and the right-hand sides are the corresponding factor incomes distributed to labor $L$ and capital $K$.

The system of equations above has 16 equations in 16 unknown variables: $w$, $r, p_{B}, p_{N}, K_{B}, L_{B}, K_{N}, L_{N}, B_{K}, B_{L}, N_{K}, N_{L}, B, N, U_{L}$, and $U_{K}$. However, in light of the Walras' Law only 15 equations are independent. 
So the system is determinate only if all the prices are treated as relative prices, relative to, say, $p_{N}$. Given the specific production functions and utility functions of the $\mathrm{CD}$ type as assumed above, our autarky GE-equation system can then be solved explicitly for each/all the 15 endogenous variables above in terms of one single parameter, namely $\alpha$. All these parametric autarky GE solutionsfor both Banana $(b)$ and Nuts $(n)$ countries-are given in Table 1 below (with further explanations).

The following observations are important:

1) When $\alpha=1 / 2$ : The two production functions become identical. Also the consumer tastes are such that both bananas $B$ and nuts $N$ are equally appreciated.

2) When $\alpha>1 / 2$ : The output elasticity of $N$ with respect to capital is larger than that with respect to labor. It follows that the $N$ sector becomes capital intensive, and the $B$ sector labor intensive. It also means that the utility elasticity of nuts in Banana country (b), (3)-(4), is higher than that of bananas, implying a stronger taste for $N$ than for $B^{6}$.

3) The larger the parameter $\alpha$ (exceeding 1/2), the higher the capital intensity of the capital-intensive $N$ sector is, also the higher the labor intensity of the $B$ sector by comparison, and vice versa $a^{7}$. This in effect is a corollary to 2 ), and an increasingly higher $\alpha$ also requires an increasingly higher taste for $N$ than for $B$, and vice versa ${ }^{8}$.

The observations above lead to certain particular relations of optimal factor allocations and output mix known, respectively, as the so-called "contract curve" CC and the "production possibilities frontier" PPF. The CC and PPF, however, are pre-GE outcomes derived from the technology/endowment Assumptions (A1-A4) only. Although the tastes/preferences (A-5) are yet to be introduced for autarky general equilibrium to obtain, note how CC may be related to PPF.

\subsection{Equi-MRTS to Yield MRT (CC Related to PPF): Pre-GE Relations}

Focusing on autarky, when $\alpha>1 / 2 \quad(\alpha<1 / 2)$, we shall see that our contract curves are concave (convex) curves in the factor space $(L, K)$. The optimal sectoral factor allocation condition is given by combining (9) and (10):

$$
M R T S_{B}=M R T S_{N} \text { between Sectors } B \text { and } N \text {. }
$$

This equation is further by $(9-10)$ written as:

$$
\left\{-\frac{\mathrm{d} K_{B}}{\mathrm{~d} L_{B}}=\frac{K_{B}}{L_{B}} \frac{\alpha}{1-\alpha}\right\}=\left\{-\frac{\mathrm{d} K_{N}}{\mathrm{~d} L_{N}}=\frac{K_{N}}{L_{N}} \frac{1-\alpha}{\alpha}\right\},
$$

${ }^{6}$ If $\alpha<1 / 2$, the $N$ sector becomes labor intensive, and the $B$ sector capital intensive.

${ }^{7}$ That is, the lower the $\alpha$ (below $1 / 2$ ), the higher the labor intensity of the labor-intensive $B$ sector. ${ }^{8}$ There exists no priori reason for any particular good produced with any given factor input more intensively used than the other factor, to be also preferred more, consumed more than the other good. Indeed no technology parameter $\alpha_{T}$ need be identical to preference parameter $\alpha_{P}$. The only reason for assuming the preference parameter identical to the technology parameter is to minimize the number of parameters used to just one, and nothing else. Subject assumption is a mere expediency. We could begin with a more conventional, more inclusive assumptions set. But applying Occam's razor leads to the present choice of the single parameter $\alpha$. Also cf. Basmann [21] for his reference to the "freedom of (introducing) assumptions". 
Hence we get,

$$
\frac{K_{B}}{L_{B}} \frac{\alpha}{1-\alpha}=\frac{K_{N}}{L_{N}} \frac{1-\alpha}{\alpha} .
$$

which combined with the conditions of a given total endowments of $L$ and $K$, both assumed to be unity (11-12) yields a unique relation between $L_{N}$ and $K_{N}$ (and hence between $L_{B}$ and $K_{B}$ ) in the factor space $(L, K)$ :

$$
K_{N}=\frac{1}{1-\left(1-\frac{1}{\alpha}\right)^{2}\left(1-\frac{1}{L_{N}}\right)}=\frac{L_{N}}{L_{N}+\left(1-\frac{1}{\alpha}\right)^{2}\left(1-L_{N}\right)}
$$

Geometrically, the expression (19) represents concave or convex curves that are rectangular hyperbolas, cf. Allen [[20], p.74]. Thus the upshot is a familiar Edgeworth box diagram of a contract curve (CC), shown by panel a) in Figure 1 . The CC (19) is strictly concave for the CD parameter $\alpha>1 / 2$, assumed for the time being to apply to either one of the two technologically clone nations. This concave curve CC is the standard locus of back-to-back tangency points of the two-good isoquant curves.

Connected to (19) is another curve (always concave), relating the ordered efficient pairs $\left(L_{N}, K_{N}\right)$ from the CC curve to their ordered pair $(B, N)$ of maximum outputs, shown in a separate quadrant $(B, N)$ in Figure 1 . This PPF curve, called production possibilities frontier, may formally be given by an implicit function $\mathrm{T},(20)^{9}$.

$$
N=T(B ; \alpha)
$$

Regarding (19) and (20), both CC and PPF are uniquely given for any given CD parameter $\alpha$ as aforementioned (See (3) and (4) supra). Thus, given the technologies underscoring $\alpha$ being the same for the two countries, their CCs are the same, and so are the PPFs ${ }^{10}$.

Consider now a point $\left(L_{N 0}, K_{N 0}\right)$ on CC and another related point $\left(B_{0}, N_{0}\right)$ on PPF, both points labeled $E_{n}$, Figure 1 panels (a) and (b) above. These two related points illustrate an autarkic equilibrium for the Nutties that love $N$ more than $B$, rather than do the Bananans as trade partners to be discussed in the next section. This is because even though the technologies represented by the two curves $\mathrm{CC}$ and PPF are identical, final equilibrium points on them are to be identified/determined by tastes. Thus, if bananas are preferred to nuts instead, then more bananas than nuts must be produced/consumed, and the final general equilibrium points must be determined and represented elsewhere in Figure 1 above, not at $E_{n}$.

${ }^{9}$ This curve (points) of the implicit function $T$, (20), mapping ( $B ; \alpha$ ) to $N$, is derived formally from Equations ((1), (2), (11), (12) and (19)) for the expanded domain of $(1>\alpha>0)$, which can be numerically solved fully by computer.

${ }^{10}$ The more precise, yet more general, relations between the two curves, and more importantly on final equilibrium points thereon are to be shown in more detail below in Figure 4 \& Figure 5 for varying values of $\alpha$ in $(0,1)$. Jensen [[22], pp. 66-69] also discusses how PPF and CC curves for $\mathrm{CD} / \mathrm{CES}$ autarky economies may be derived from the relative factor prices, commodity prices, and capital/labor ratios. 


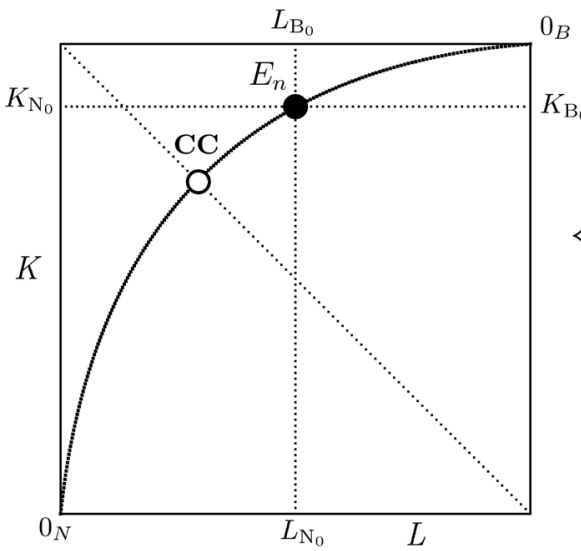

(a)

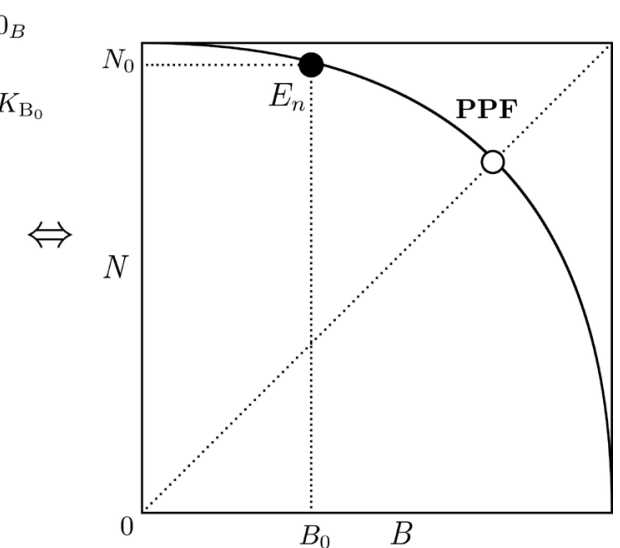

(b)

Figure 1. The CC and PPF curves, upon which general equilibrium points are identified by taste, given $\alpha>1 / 2$. (a) Optimal factor allocations; (b) optimal output mixes.

Though not shown explicitly upon Figure 1, if the Bananans have a strong taste for bananas, they must allocate more resources to produce (and consume) more bananas than the Nutties do. Because of our simplified one parameter model of $\alpha$, the Bananans' strong taste for bananas require their utility elasticity of bananas to be represented by $1-\alpha<1 / 2$ so as to make them love more bananas than nuts.

These distinct tastes of the two otherwise clone nations (with $\alpha>1 / 2$ ) can thus be represented, on both PPF and CC curves identified either above or below midpoints thereof, by the Nutties' taste $\alpha>1 / 2$ and the Bananans' taste $(1-\alpha)<1 / 2$, respectively. Specifically, the partitioned parts (of points on CC and PPF) above their midpoints represent the Nutties' equilibrium, and the parts below represent the Bananans' counterpart optimum, to be explained more fully in the next section.

Given the Nutties' taste parameter $\alpha>1 / 2$, cum the technology parameter $\alpha>1 / 2$, the share of returns to capitalist (rental income) must strictly exceed $1 / 2$ and the share of wage income, by comparison, fall below $1 / 2$ in the Nuts country. It then follows that the Nuttie workers under autarky must be poorer than their capitalist neighbors accordingly ${ }^{11}$.

Specifically, wage rate given by factor allocation identified at any point along the CC curve above its midpoint (circled in white above) must be strictly lower than unity. At this white-circled point, MRTS is required to be unity ${ }^{12}$. The corresponding wage rate at this point is unity. Not only relative factor price is unity at this point on $\mathrm{CC}$, but also unity is the corresponding relative product price identified at a point on the PPF on the right ${ }^{13}$.

\footnotetext{
${ }^{11} \mathrm{By}$ the same token, given the Bananans' distinct taste parameter $(1-\alpha)<1 / 2$, cum the same technology parameter $\alpha>1 / 2$ (same as the Bananan's), the share of capitalist rental income must fall below $1 / 2$ and the share of wage income, by comparison, must exceed 1/2. Hence, the Bananan workers under autarky must be strictly richer than their capitalist neighbors.

${ }^{12}$ This follows because the CC curve is the loci of the two-sector iso-quant curves' tangency points facing to one another. The slope of the tangency at the point of intersection of CC and the 45 degree auxiliary line $K=1-L$ must be unity.

${ }^{13}$ See Table 1 for complete analytical solutions in terms of $\alpha$.
} 
Thus, on CC and PPF above one single parameter $\alpha>1 / 2$ can be used to identify two points above and two points below the two white circles, respectively. The two such distinct points along PPF show two distinct national tastes and two related points along $\mathrm{CC}$, by contrast, represent distinctive resource allocations of two technologically clone nations. The four points identifiable by just one parameter $\alpha>1 / 2$ along PPF and CC above thus point to equilibrium resource allocations and related output mixes of two clone nations, having different tastes, however.

Related observations of particular importance are:

1) Even within the confines of our "ideal types" model, "ruthless outcomes" of income distribution aforementioned are unavoidable unless $\alpha=1 / 2$, which requires two clone nations to be identical in both tastes and technologies. If people have an unbalanced and skewed taste, for either nuts or bananas, the degree of bias will, by our basic assumption, influence the methods of production. The stronger the skewed taste, the greater the differences in the methods of production will be in equilibrium between the two sectors. Thus, the more the $\alpha$ deviates from $\alpha=1 / 2$, the greater the income inequality.

2) Such a ruthless outcome is inevitable despite the larger pie of nuts and bananas, under the conditions of distinctively different methods of production.

3) No ruthless outcomes will arise only if methods of production are assumed identical, $\alpha=1 / 2$.

4) Only under such special (technological) conditions everybody will be equally remunerated, but equally poor as well, regardless of tastes.

The two autarky economies with all their associated endogenous variables are represented by their explicit solutions in terms of the single parameter $\alpha$ in Table 1-see Appendix.

\section{The Open Economies: $2 \times 2 \times 2$ GE Model}

\subsection{Assumptions}

The simplest possible $2 \times 2 \times 2$ general equilibrium model of trade, once again by the same one single $\mathrm{CD}$ parameter, is now in order, but with basically the same assumptions as those introduced in Section 1. Assumptions with an asterisk below, however, should be noted for differences from the preceding assumptions.

$(\mathrm{A} 2-1)^{*}$ There are two clone nations: Nuts Country and Banana Country, respectively labeled $n$ and $b$.

(A2-2) Same as (A1-2).

(A2-3) Same as (A1-3).

(A2-4) Same as (A1-4).

$(\mathrm{A} 2-5)^{*}$ The two countries' national tastes are different such that $n$ 's taste is represented by the same CD parameter of $\alpha$ for nuts and $(1-\alpha)$ for bananas, whereas the $b$ 's taste is reversed; the $b$ 's taste for nuts is given by $(1-\alpha)$, and that for bananas by $\alpha$.

The assumed differences, both in methods of production and in tastes, are 
Table 1. Two-country autarky equilibrium: Solutions given by preference/technology parameter $\alpha: 0<\alpha<1$.

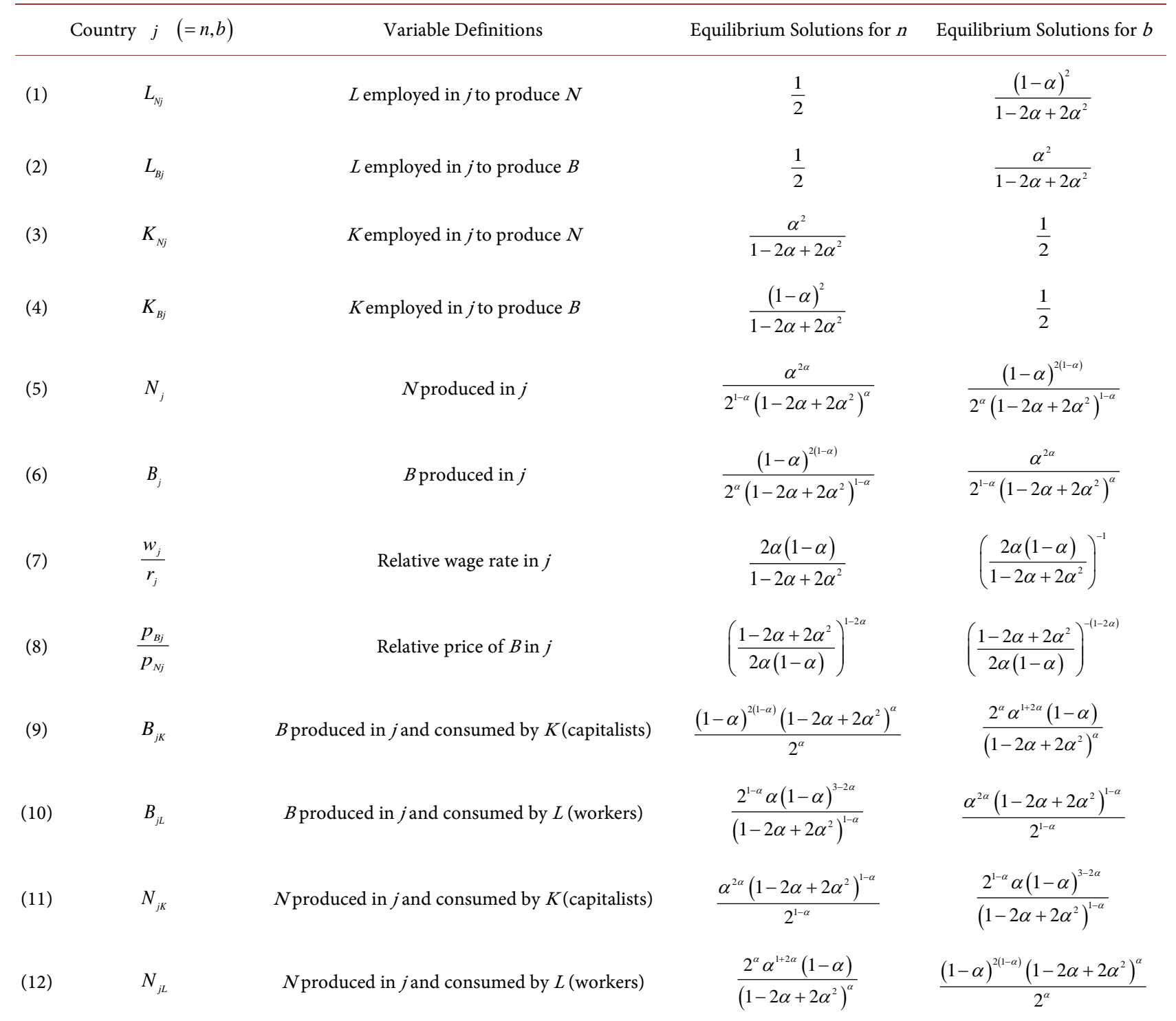

NOTE: In the table $M R T_{j} \equiv\left(-\frac{\mathrm{d} N_{j}}{\mathrm{~d} B_{j}}\right)$ and $M R S_{j} \equiv\left(-\frac{\mathrm{d} N_{j}}{\mathrm{~d} B_{j}}\right)$, then $M R T_{j}=M R S_{j}=\frac{p_{B j}}{p_{N j}},($ Country $j=b, n)$ at the autarky equilibrium. Also note that given the unrestricted domain for $\alpha$, each country may prefer either one of the two goods to the other. Thus, if $\alpha<1 / 2$, contra the Figure 1 assumption of $\alpha>1 / 2$, the Nutties may love bananas more than nuts, and vice versa for Bananans.

thus represented by one single CD parameter $\alpha$, signifying both technology and taste/preference. Pursuant to these assumptions we now proceed to derive $2 \times 2 \times 2$ open general equilibrium conditions of production, related resource allocation/distribution, and consumption.

\subsection{The $2 \times 2 \times 2$ One CD Parameter Model of Trade}

We begin by defining the two clone countries' production functions in terms of only one $\mathrm{CD}$ parameter $\alpha$ to differentiate the two sectors' production functions:

The $B$ Sector: 


$$
\left.B_{j}=L_{i j}^{\alpha} K_{i j}^{1-\alpha}, \quad i=B, N(\text { Sectors }) ; j=b, n \text { (Countries }\right)
$$

The NSector:

$$
N_{j}=L_{i j}^{1-\alpha} K_{i j}^{\alpha}, \quad i=B, N(\text { Sectors }) ; j=b, n \text { (Countries) }
$$

where the subscripts $i$ and $j$ stand for the sector $i$ (=B for bananas, $N$ for nuts) and the Country $j$ (= $b$ for Bananans, $n$ for Nutties), respectively. Subject to these production functions the optimization conditions for factor allocations yield a convex production possibilities set with its frontier PPF: concave function from $B_{j}$ to $N_{j}$.

Given $\alpha>1 / 2 \quad$ (or $<1 / 2$ ), either one of the two identical PPFs for the clone countries $b$ and $n$ may be transposed and made tangent to the other PPF for purposes of international trade. The two such PPFs that are tangent to one another and back-to-back are illustrated by Ohta [[18], Figure 2.3] as a point for productive optimum under free trade. It is then straightforward to identify the related points for consumptive optimum after trade for the trading partner countries $b$ and $n$, respectively, given their respective tastes: $\alpha$ and $(1-\alpha)$. (See the 8 such optimum points demonstrated by the solutions (9) through (16), Table 2 infra.)

Let us next consider the two countries' indifference curves that are derived from their national utility functions represented by the same single parameter $\alpha$ as follows.

The Bananans:

$$
U\left(B_{b}^{c}, N_{b}^{c}\right)=\left(B_{b}^{c}\right)^{\alpha}\left(N_{b}^{c}\right)^{1-\alpha}
$$

The Nutties:

$$
U\left(B_{n}^{c}, N_{n}^{c}\right)=\left(B_{n}^{c}\right)^{1-\alpha}\left(N_{n}^{c}\right)^{\alpha}
$$

Note carefully here that although $U$ s of the two national consumptions $B_{b}^{c}$ and $N_{b}^{c}$ for country $b$, and $B_{n}^{c}$ and $N_{n}^{c}$ for country $n$ are defined by the identical parameter $\alpha$, the larger the $\alpha>1 / 2$, the stronger are both the Nutties' taste for nuts and the Bananans' taste for bananas ${ }^{14}$. Total consumptions by individual factor suppliers must add up to total outputs $B_{j}$ and $N_{J}$ produced in both countries. Thus, individual factor consumptions (9) to (16) on Table 2 infra are given by $B_{b}^{c}=B_{n K_{b}}+B_{n L_{b}}+B_{b K_{b}}+B_{b L_{b}}, \quad N_{b}^{c}=N_{n K_{b}}+N_{n L_{b}}+N_{b K_{b}}+N_{b L_{b}}$, $B_{n}^{c}=B_{n K_{n}}+B_{n L_{n}}+B_{b K_{n}}+B_{b L_{n}}$, and $N_{n}^{c}=N_{n K_{n}}+N_{n L_{n}}+N_{b K_{n}}+N_{b L_{n}}$.

The conditions for consumptive optimum are then given by:

$$
M R S_{B N j}=\frac{p_{B j}}{p_{N j}}, \quad j=b, n(\text { Countries })
$$

The related conditions for optimizing factor allocation are given by:

$$
\operatorname{MRTS}_{B N j}=\frac{w_{j}}{r_{j}}, \quad j=b, n(\text { Countries })
$$

\footnotetext{
${ }^{14}$ Conversely, if $\alpha<1 / 2$, the stronger are both the Nutties' taste for bananas and the Bananans' taste
} for nuts. 
Given the specific production functions and utility functions of the CD type as assumed above, the system can then be solved for all the 16 endogenous variables above in terms of one parameter, namely $\alpha$ in each country.

\section{The $2 \times 2 \times 2$ GE Model of Trade Compared to Autarky}

Remember that the system of equations set forth in Section 1 applies to either country $b$ or $n$ before trade (autarky). It is now solvable again in terms of $\alpha$ only $(1>\alpha>0)$ for the 12 variables $L_{j N}, L_{j B}, K_{j N}, K_{j B}, N_{j}, B_{j},(w / r)_{j}$, $\left(p_{B} / p_{N}\right)_{j}, B_{j K}, B_{j L}, N_{j K}$, and $N_{j L}(j=b, n)$, are summarized in Table 1.

Numerical solutions to the model are also derivable. Figure 2 illustrates the autarky solution set of outputs $(B, N)$ as a unique function of $\alpha \in(0,1)$. It illustrates how a change in $\alpha$ deviating either above or below 1/2 may generate a unique trade-off between production of nuts and bananas, but only up to a certain critical point of $\alpha$, beyond which both outputs (and consumptions) of $B$ and $N$ start to increase with no trade-offs thereafter.

Thus, if both the methods of production and tastes for goods are different enough $(\alpha<0.18$ or $\alpha>0.82)$, then the greater the differences in taste and technology, the greater is the number of both goods under autarky. This is not to say, however, that a small difference in taste or technology is bad news. Any small deviation from $\alpha=1 / 2$ indeed yields a strict increase in national welfare as implied by a solid locus staying above the linear 45 degree line representing PPF in the case $\alpha=1 / 2$, Figure 2. Here the solid (upper-left) curve in Figure 2 represents a (one-to-one) function from a parameter set $\alpha=[1 / 2,1]$ to a locus set $(B, N)$ of equilibrium output mixes.

This particular set corresponds to, and is also shown by, a U-shaped non-monotonic $B_{A T n}\left(=N_{A T b}\right)$ curve vis-a-vis a monotonically increasing $N_{\text {ATn }}\left(=B_{\text {ATb }}\right)$ curve in Figure 3, which shows how a strictly stronger preference for nuts than bananas yields the equilibrium output mix of $(B, N)$ over the parameter set $\alpha=[1 / 2,1]$. The solid (lower-right) curve in Figure 2, by comparison, is the locus $(B, N)$, which is now shown by a non-monotonic $N_{\text {ATn }}\left(=B_{\text {ATb }}\right)$ curve vis-a-vis a monotonically diminishing $B_{\text {ATn }}\left(=N_{\text {ATb }}\right)$ curve in Figure 3. This part of Figure 3 is derived from $\alpha=[0,1 / 2]$, which presupposes a stronger preference for bananas than nuts.

Also depicted here, strictly above the two asymmetric curves $N_{A T n}\left(=B_{A T b}\right)$ and $B_{A T n}\left(=N_{A T b}\right)$, are two symmetric U-shaped curves. Of the two, note the lower curve is a vertical sum of the $N_{A T b}+N_{A T n}$ and $B_{A T b}+B_{A T n}$, hence labeled $N_{A T n}+N_{A T b}\left(=B_{A T n}+B_{A T b}\right)$. It depicts the aggregate output either bananas or nuts, produced by the two countries $\mathrm{n}$ and $\mathrm{b}$, under conditions of autarky. The higher, topmost U-shaped curve, by comparison, depicts the aggregate world output (of either $N$ or $B$ ) still greater under free trade than under autarky.

As a further related note to Figure 3, if and when the parameter $\alpha$ happens to be either large enough to exceed a certain critical value aforementioned of 0.82 , viz., $\alpha=0.82$ or small enough to be under $0.18, \alpha=0.18$, which 


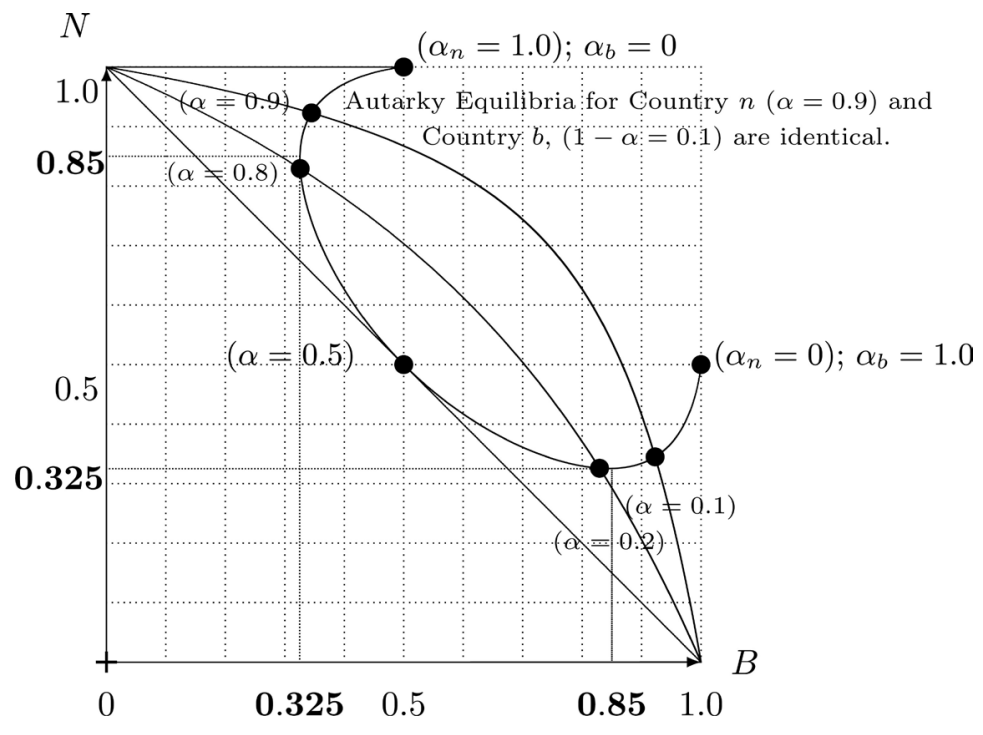

Figure 2. Autarky Equilibrium Loci $(B, N)$ for both Countries $n$ and $b$ : The PPF curves drawn for $\alpha=0.9(0.1) ; 0.8(0.2) ; 0.5$, upon which superimposed are equilibrium loci of goods $B$ and $N$ in countries $n$ and $b$ shown by black circles.

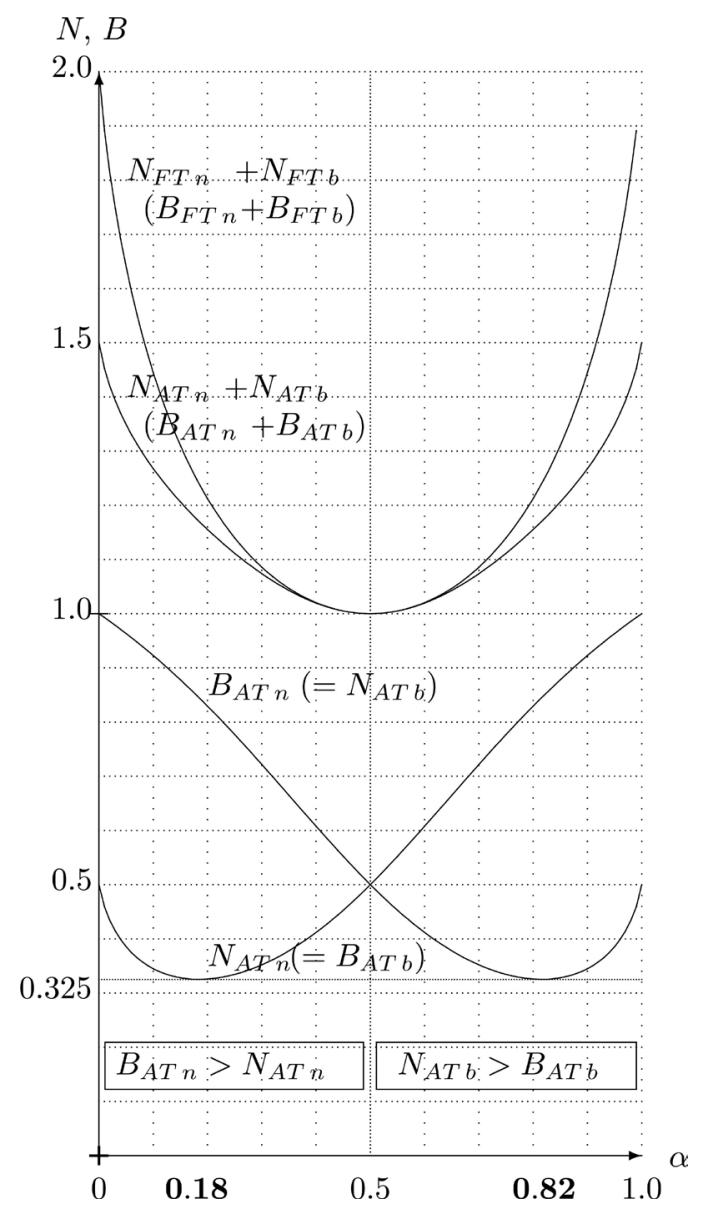

Figure 3. Nuts $(N)$ and Bananas $(B)$ produced before and after trade: Individual nations' outputs and their aggregates. Figure note: Over the sub-domain of $\alpha(0,0.5)$, more $B(N)$ is produced/consumed than $N(B)$, while over the other sub-domain of $\alpha(0.5,1.0)$, more $N(B)$ than $B(N)$, in country $n(b)$. Also illustrated are aggregate outputs before and after trade, given $\alpha[0,1]$. Here $A T$ stands for "Autarky", and FT for "Free Trade". 
numerical values are model-specific ${ }^{15}$, then any further deviation thereof in $\alpha$ will increase the production of both nuts and bananas in a given clone country, be it the Banana Country or the Nuts Country. However, insofar as $\alpha$ remains within the normal domain in-between $0.18<\alpha<0.82$, then there will be strict trade-offs between nuts and bananas produced as $\alpha$ changes in either direction. Thus, for example, if the value of $\alpha$ approaches 0.18 or larger, then the output of bananas must keep declining while nuts start to increase (along the $\mathrm{U}$-shaped curves of $B_{A T n}\left(=N_{A T b}\right)$ and $N_{A T n}\left(=B_{A T b}\right)$, respectively.)

Within this normal domain (reflecting more balanced tastes and technologies), nuts increase with the parameter value $\alpha$ more than bananas decrease and the former output surpasses the latter output as long as $\alpha$ remains to exceed 1/2. The nuts production keeps increasing while bananas keep decreasing until $\alpha$ reaches 0.82. Remember in this connection that the larger $\alpha$ implies not only a higher output elasticity of capital in the production of nuts, but also a stronger preference for nuts. So, more nuts are produced than bananas. This is why the aggregate two-country output (of either $N$ or B, i.e., $N_{A T n}+N_{A T b}$ or $B_{A T n}+B_{A T b}$, Figure 3) starts to increase as $\alpha$ deviates from $\alpha=1 / 2$ to either increase or decrease.

It warrants emphasis, however, that despite a strong taste for nuts, along with a high technology parameter $\alpha$, high enough to approach unity, substantial amounts of bananas are also produced nonetheless. This is due to the high and low technology parameter effect of differences in the methods of production in the two assumed sectors. Related to this, and perhaps more important, is a certain intrinsic property of the CD function. Its factors are essentials as well as substitutes. This is because each factor is indispensable for the other. (Labor is as indispensable as capital is).

However, once again, this is not to say that everybody will be happier if only national welfare increases with $\alpha$ beyond $1 / 2$ (or with smaller $\alpha$ below 1/2). This is because unless $\alpha=1 / 2$ any taste differentials tend to bring about unequal income distribution under the market conditions of perfect competition. Behind the locus of $\left(B_{n}, N_{n}\right)$ as well as of $\left(B_{b}, N_{b}\right)$, in Figure 2, it is to be noted, are the solutions to the corresponding variables, depicted in Figure 3, all in terms of $\alpha$. Related to these outcomes are interesting observations on factor allocations of $(L, K)$ for two clone nations with different national tastes. Namely, regardless of $\alpha$, the related allocation of a certain factor that changes with $\alpha$, the other factor allocation remains unaltered. Moreover, it remains constant at just half of its total endowment ${ }^{16}$ !

\footnotetext{
${ }^{15}$ The numerical values derived here are the model-specific (to the single $\alpha$ assumed). It goes without saying that a nonempty set of the methods of production that generate a strictly positive output effects in both (all) sectors may be derivable from the more general parametric conditions than the present single parameter. Cf. notes 7 and 8 , however.

${ }^{16}$ Intuitive interpretation thereof is as follows. Insofar as factor intensity remains neutral, as in case of $\alpha=1 / 2$, factor allocations to either sectors should remain equal, i.e., $1 / 2$ in the present model. Given this reference departure point, the higher (lower) the $\alpha$ is, the higher (lower) the utilization of the higher (lower) intensive factor will be. Since a more or less utilization is defined by deviation from this fixed ratio of $1 / 2$, or half and half utilization of labor and capital, any deviation thereof must be defined relative to this reference half. Thus, either more or less intensively utilized factor alone moves while the other factor remains invariant at $1 / 2$ within each one of the two sectors.
} 
The particular factor is that used more intensively than the other factor. Thus in our present example of the nuts sector that uses capital more intensively than labor, the greater the $\alpha$ (implying greater taste for nuts as well as greater output elasticity of capital), the greater the output and hence capital input in the capital-intensive sector. However, the other factor does not increase at all, remains instead its sector allocation constant, (1/2) as shown in Figure 4.

Since the greater $\alpha$ implies the greater taste for bananas, as in the Banana Country, then the same greater parameter $\alpha$ requires the smaller taste for bananas in the Nuts Country, being represented by $1-\alpha$, i.e., lower taste for bananas. If the Nuts Country's more labor-intensive nuts sector is in greater demand, then more and more labor is needed to produce nuts while capital input remains constant, as in Figure 5.

Related to impacts of $\alpha$ upon total as well as sectoral outputs (Figure 3), and factor allocations (Figure 4, Figure 5) are the outcomes of income distribution. Let us now focus our attention on comparing factor prices between two factors within each country (intra-nationally) and between two clone countries (internationally) endowed with different national tastes.

Figure 6 depicts the computed results of relative factor prices $(w / r)$ for two countries as a monotone function of $\alpha$ under conditions of both autarky and free trade as well. Figure 6 does indeed reveal the remarkable implications of free trade vs. autarky-as does Figure 7 for the corresponding factor allocations

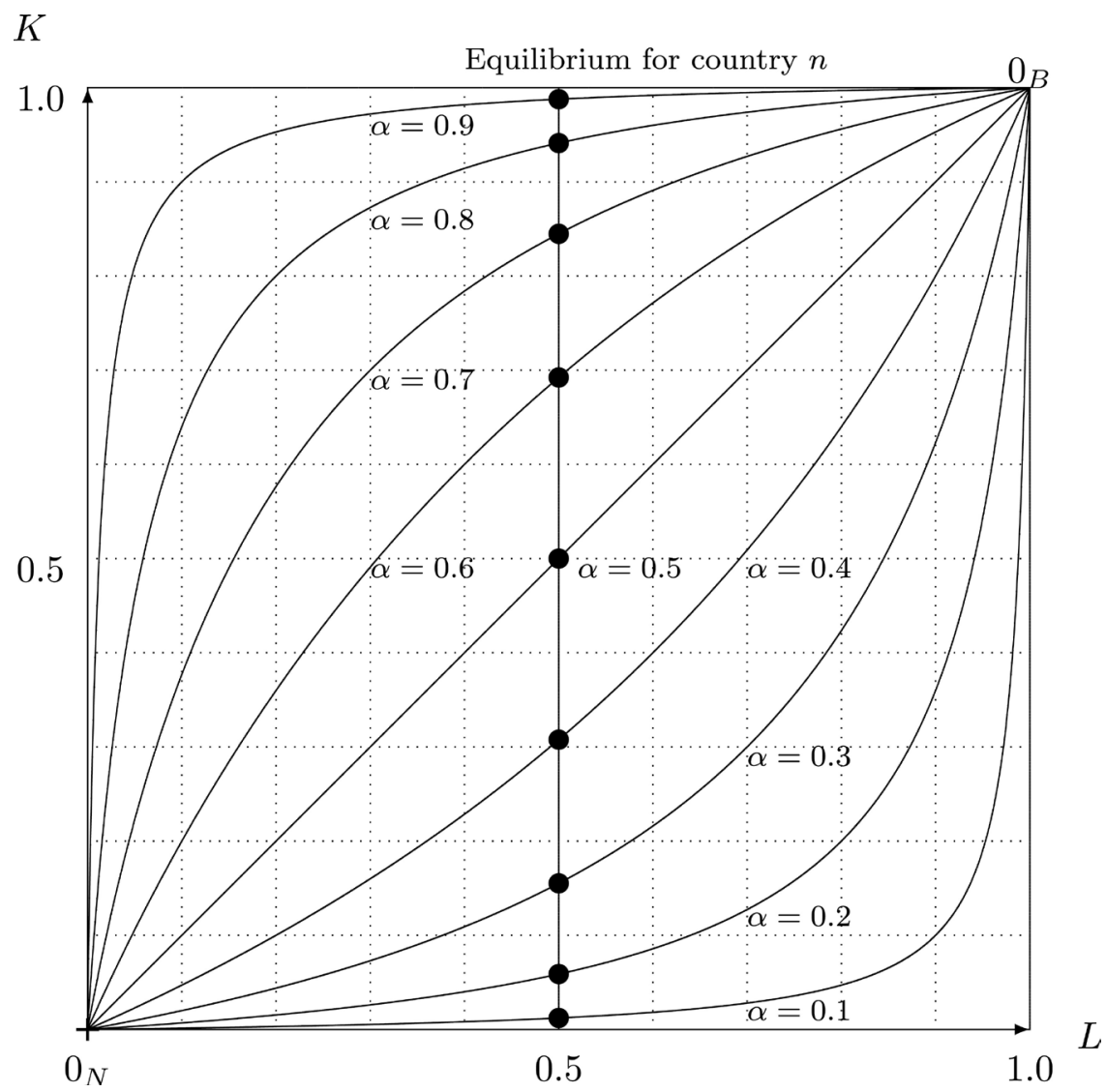

Figure 4. Autarky equilibria in factor market space for varying $\alpha$ in country $n$. 


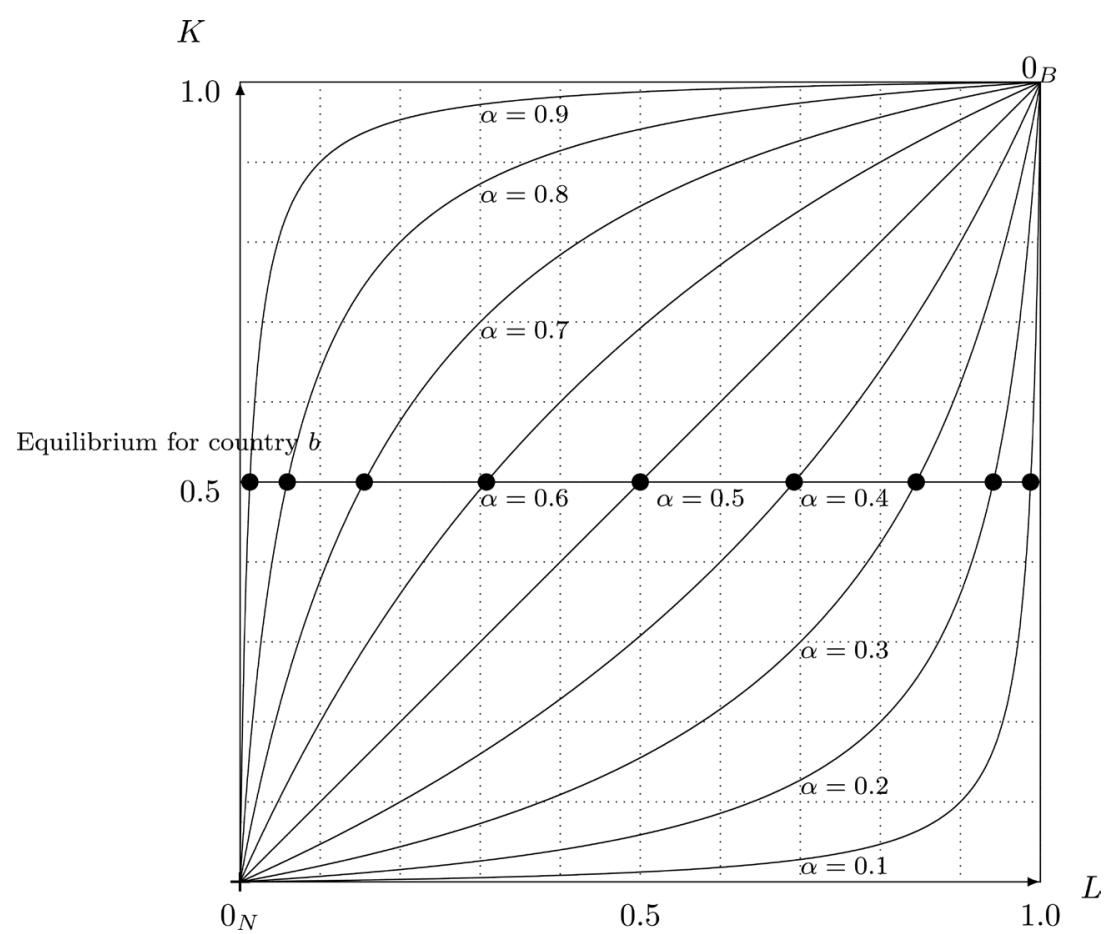

Figure 5. Autarky equilibria in factor market space for varying $\alpha$ in country $b$.

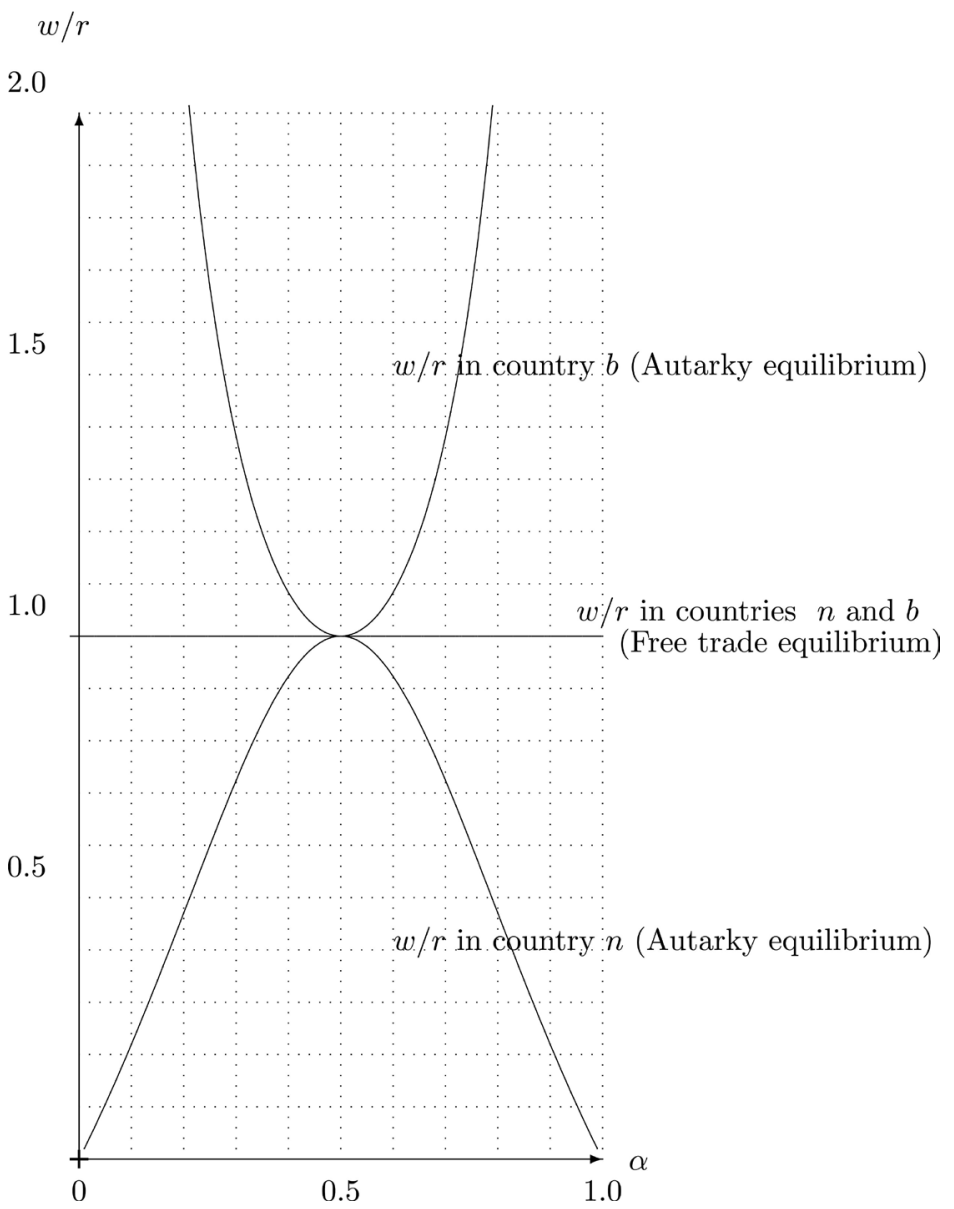

Figure 6. Impacts of taste/technology parameter $\alpha$ upon international as well as intranational income distribution. 
loci. In the case of free trade between countries $b$ and $n$, note that the system of equations set forth in Section 1 can be basically reapplied to both countries $b$ and $n$ under free trade. It is once again solvable in terms of $\alpha$ only. The free trade GE solutions of our $2 \times 2 \times 2 \mathrm{CD}$ model are summarized in Table 2, cf. Appendix ${ }^{17}$.

In comparing Table 1 and Table 2, note the following:

1) When $\alpha=1 / 2$, the two countries are genuine clones producing both nuts and bananas equally and distributing them equally between workers and capitalists. So, $w / r=1$.

2) For any $\alpha>1 / 2, w / r$ is strictly less than unity in one country (Nuts

Table 2. Two-country free-trade equilibrium: Given by preference/technology parameter $\alpha: 0<\alpha<1$.

\begin{tabular}{|c|c|c|c|c|}
\hline & Country $j(=n, b)$ & Variable Definitions & Equilibrium Solutions for $n$ & Equilibrium Solutions for $b$ \\
\hline (1) & $L_{N j}$ & $L$ employed in $j$ to produce $N$ & $1-\alpha$ & $1-\alpha$ \\
\hline$(2)$ & $L_{B j}$ & $L$ employed in $j$ to produce $B$ & $\alpha$ & $\alpha$ \\
\hline (3) & $K_{N j}$ & $K$ employed in $j$ to produce $N$ & $\alpha$ & $\alpha$ \\
\hline$(4)$ & $K_{B j}$ & $K$ employed in $j$ to produce $B$ & $1-\alpha$ & $1-\alpha$ \\
\hline$(5)$ & $N_{j}$ & $N$ produced in $j$ & $\alpha^{\alpha}(1-\alpha)^{1-\alpha}$ & $\alpha^{\alpha}(1-\alpha)^{1-\alpha}$ \\
\hline (6) & $B_{j}$ & $B$ produced in $j$ & $\alpha^{\alpha}(1-\alpha)^{1-\alpha}$ & $\alpha^{\alpha}(1-\alpha)^{1-\alpha}$ \\
\hline (7) & $\frac{w_{j}}{r_{j}}$ & Relative wage rate in $j$ & 1 & 1 \\
\hline (8) & $\frac{p_{B j}}{p_{N j}}$ & Relative price of $B$ in $j$ & 1 & 1 \\
\hline (9) & $N_{j K_{n}}$ & $N$ produced in $j$ and consumed by $K$ (capitalists) in $n$ & $\begin{array}{c}0.5 \alpha^{\alpha+1}(1-\alpha)^{1-\alpha} \\
\text { (Domestic Demand) }\end{array}$ & $\begin{array}{l}0.5 \alpha^{\alpha+1}(1-\alpha)^{1-\alpha} \\
\text { (Export Demand) }\end{array}$ \\
\hline (10) & $B_{j K_{n}}$ & $B$ produced in $j$ and consumed by $K$ (capitalists) in $n$ & $\begin{array}{c}0.5 \alpha^{\alpha}(1-\alpha)^{2-\alpha} \\
\text { (Domestic Demand) }\end{array}$ & $\begin{array}{l}0.5 \alpha^{\alpha}(1-\alpha)^{2-\alpha} \\
\text { (Export Demand) }\end{array}$ \\
\hline (11) & $N_{j L_{n}}$ & $N$ produced in $j$ and consumed by $L$ (workers) in $n$ & $\begin{array}{c}0.5 \alpha^{\alpha+1}(1-\alpha)^{1-\alpha} \\
\text { (Domestic Demand) }\end{array}$ & $\begin{array}{l}0.5 \alpha^{\alpha+1}(1-\alpha)^{1-\alpha} \\
\text { (Export Demand) }\end{array}$ \\
\hline (12) & $B_{j L_{n}}$ & $B$ produced in $j$ and consumed by $L$ (workers) in $n$ & $\begin{array}{c}0.5 \alpha^{\alpha}(1-\alpha)^{2-\alpha} \\
\text { (Domestic Demand) }\end{array}$ & $\begin{array}{l}0.5 \alpha^{\alpha}(1-\alpha)^{2-\alpha} \\
\text { (Export Demand) }\end{array}$ \\
\hline (13) & $N_{j K_{b}}$ & $N$ produced in $j$ and consumed by $K$ (capitalists) in $b$ & $\begin{array}{l}0.5 \alpha^{\alpha}(1-\alpha)^{2-\alpha} \\
\text { (Export Demand) }\end{array}$ & $\begin{array}{c}0.5 \alpha^{\alpha}(1-\alpha)^{2-\alpha} \\
\text { (Domestic Demand) }\end{array}$ \\
\hline (14) & $B_{j K_{b}}$ & $B$ produced in $j$ and consumed by $K$ (capitalists) in $b$ & $\begin{array}{l}0.5 \alpha^{\alpha+1}(1-\alpha)^{1-\alpha} \\
\text { (Export Demand) }\end{array}$ & $\begin{array}{c}0.5 \alpha^{\alpha+1}(1-\alpha)^{1-\alpha} \\
\text { (Domestic Demand) }\end{array}$ \\
\hline (15) & $N_{j L_{b}}$ & $N$ produced in $j$ and consumed by $L$ (workers) in $b$ & $\begin{array}{l}0.5 \alpha^{\alpha}(1-\alpha)^{2-\alpha} \\
\text { (Export Demand) }\end{array}$ & $\begin{array}{c}0.5 \alpha^{\alpha}(1-\alpha)^{2-\alpha} \\
\text { (Domestic Demand) }\end{array}$ \\
\hline (16) & $B_{j L_{b}}$ & $B$ produced in $j$ and consumed by $L$ (workers) in $b$ & $\begin{array}{l}0.5 \alpha^{\alpha+1}(1-\alpha)^{1-\alpha} \\
\text { (Export Demand) }\end{array}$ & $\begin{array}{c}0.5 \alpha^{\alpha+1}(1-\alpha)^{1-\alpha} \\
\text { (Domestic Demand) }\end{array}$ \\
\hline
\end{tabular}

NOTE (1): $M R T=M R S=\frac{p_{B j}}{p_{N j}}=1, \quad($ Country $j=n, b) \quad$ at the free trade equilibrium between Countries $n$ and $b$. NOTE (2): (5) $=(9)+(11)+(13)+(15)$ for good $N$, and (6) $=(10)+(12)+(14)+(16)$ for good $B$.

\footnotetext{
${ }^{17}$ Table 2, in comparison with Table 1, is based on a generalized assumption on tastes: the Bananans may prefer either $B$ or $N$, and the Nutties likewise, either $B$ or $N$, while maintaining national taste differences (using just one parameter $\alpha$ with the generalized domain $[0,1]$ ).
} 
Country here) and greater than unity in the other country (Banana Country). This implies that the workers in one country are poorer and those in the other country richer, respectively, than their capitalists.

3) The intra-national income gaps furthermore widen increasingly within each of the two clone countries as $\alpha$ increases.

4) Thus, it warrants emphasizing that no international taste differential is needed for intra-national income inequality to occur. If only a skewed taste for one good over another exists, then intra-national income disparity is inescapable insofar as output elasticity is not equal to $1 / 2$.

5) It is thus not free trade per se that would cause income inequality, inasmuch as a domestic market can create horrendous factor price differentials even with no free trade.

6) Under autarky not only intra-national income gaps but also international income gaps widen increasingly with $\alpha$. Thus, for example, if $\alpha$ exceeds $1 / 2$ or becomes larger, as seen from Figure 6, the Bananan workers become richer increasingly than not only their own capitalist neighbors, but also the Nuttie workers abroad (cf. line 7, Table 1).

7) Free trade, although often alleged to bring about "ruthless" outcomes, actually favors all deserving individuals with factor price equalization. Here in our model complete equalization of incomes among all equally gifted, not only internationally, but also intra-nationally. All these outcomes are depicted in Figure 6 and also in Figure 7.

Let us summarize before we conclude. Commodity prices are distinctively different before trade and so are factor prices between almost clone nations. One

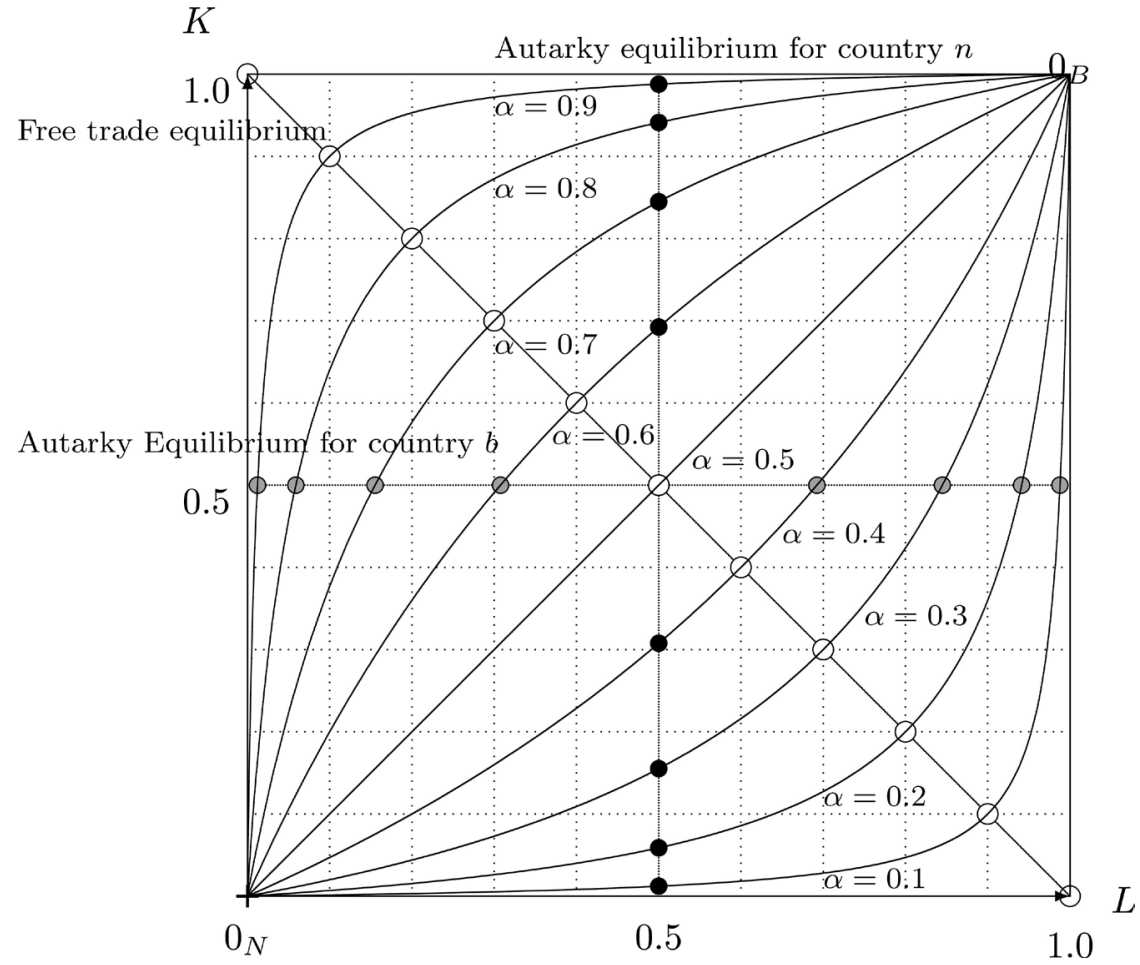

Figure 7. Free trade vs. autarky equilibria: $(K, L)$ Loci in countries $n$ and $b$. 
factor could be very expensive because the preferred commodity had forced both factors to be used for a product that they are not equally suited to produce. The opening of trade permits the two countries to specialize less in production, and more in consumption, in accordance with their different tastes. All this is accomplished by factor reallocations induced by trade, thereby equalizing both commodity and factor prices. Thus, worldwide output gains from trade arise from free trade. And all countries could increase their consumption to a higher level along with a higher national welfare level.

So, everybody ought to be happy with the outcomes of free trade as shown above. They ought to be, but aren't. The reason is that the different tastes under conditions of autarky, keep a certain factor in each nation scarcer than the other nation's identical factor even if their physical endowments are the same. Higher wages in one nation and higher rents in the other before trade, however, are nothing but quasi-rent. The market mechanism with free trade would surely wipe it out. Here lies an apparent incentive for rent seeking, so as to protect the quasi-rent as a vested interest granted under autarky government/legislation.

\section{Conclusions}

A simple GE model of production, distribution, and trade has shown some interesting rediscoveries of fundamental principles of economics, revealing the importance of intra-national differences not only in technology (even if human capability were alike), but also in taste, both skewed.

Another discovery is the importance of not only the skewed taste within a country, but also international differences in skewed tastes, in creating large income gaps not only intra-nationally but also internationally. Such ruthless outcomes of income distribution (among equally gifted individuals) are inescapable only if no trade is permitted internationally. With trade, factor price equalization necessarily yields a stumbling block (revealed by the StolperSamuelson Theorem) to the vested interest group. They benefit from a skewed national taste before trade, but lose after trade, all the more if only the skewed taste cum technology parameter $\alpha$ deviates more from $\alpha=1 / 2$, reflecting greater differences not only in the methods of production within each country but also in tastes internationally.

A related finding is how the output effect of skewed methods of production can outweigh the negative effects of skewed tastes upon a production possibility frontier. Such a net output effect of a larger $\alpha$, our single parameter assumed, may also sound surprising all the more for its paradoxical net output effect of skewed methods of production, outweighing the negative skewed taste effects upon a production possibility frontier.

A sheer skewed difference in tastes, combined with skewed technology, can aggravate devastating ruthless outcomes in income distribution, as Figure 6 demonstrates. No wonder free trade is such a difficult proposition not only in practice, but also more disturbingly in theory.

Needless to say, our research is limited by the fact that we are presenting an 
"ideal types" model of a complex real world economy. As such, we have simplified our ideal world to include only those factors that we have deemed most salient. It is possible that we have included or excluded factors that may later prove to be significant or insignificant. While we feel confident that we have presented the best possible model, further research will elucidate complexities that we may have yet overlooked.

\section{Acknowledgement}

We are greatly indebted to Murray Kemp, Martin McGuire, Wen-Jung Liang for their expertise critiques and helpful suggestions on earlier versions of this paper. Extensive comments and suggestions by both the Editor and an anonymous referee are also gratefully noted. This research was financially supported by the Japan Society for the Promotion of Science under the Grant-in-Aid for Scientific Research (C) (JSPS KAKENHI) Grant Number 24530306.

\section{References}

[1] Bhagwati, J. (1964) The Pure Theory of International Trade: A Survey. The Economic Journal, 74, 1-84.

[2] Linder, S. (1961) An Essay on Trade and Transformation. John Wiley and Sons, New York

[3] Armington, P.S. (1969) A Theory of Demand for Products Distinguished by Place of Production. International Monetary Fund Staff Papers, 16, 159-178. https://doi.org/10.2307/3866403

[4] Bhagwati, J.N. (1997) The Feuds over Free Trade, Heng Mui Keng Terrace, Pasir Panjang. Institute of Southeast Asian Studies, Singapore.

[5] Leontief, W.W. (1953) Domestic Production and Foreign Trade: The American Capital Position Re-Examined. Proceedings of the American Philosophical Society, 97, 329-349.

[6] Trefler, D. (1993) International Factor Price Differences: Leontief Was Right. Journal of Political Economy, 101, 961-987.

[7] Hübler, M. (2016) A New Trade Network Theory: What Economists Can Learn from Engineers. Economic Modelling, 55, 115-126.

[8] Santana-Gallego, M., Ledesma-Rodríguez, F. and Pérez-Rodríguez, J. (2016) International Trade and Tourism Flows: An Extension of the Gravity Model. Economic Modelling, 52, 1026-1033.

[9] Córcoles, D., Díaz-Mora, C. and Gandoy, R. (2014) Product Sophistication: A Tie that Binds Partners in International Trade. Economic Modelling, 44, S33-S41.

[10] Ohta, H. (2012) The Moral Scientific Nature of Stolper-Samuelson's Proposal to "Bribe" for Free Trade. In: Kemp, M.C., Nakagawa, H. and Uchida, T., Ed., Positive and Normative Analysis in International Economics, Essays in Honour of Hiroshi Ohta, Palgrave Macmillan, Basingstoke, Chapter 2, 17-36.

[11] Jensen, B.S. (2003) Walrasian General Equilibrium Allocations and Dynamics in Two-Sector Growth Models. German Economic Review, 4, 53-87. https://doi.org/10.1111/1468-0475.00073

[12] Stolper, W. and Samuelson, P. (1941) Protection and Real Wages. Review of Economic Studies, 9, 58-73. 
[13] Kemp, M.C. (2012) Normative Trade Theory. In: Kemp, M.C., Nakagawa, H. and Uchida, T., Eds., Positive and Normative Analysis in International Economics, 22 Essays in Honour of Hiroshi Ohta, Palgrave Macmillan, Basingstoke, Chapter 1, 7-16. https://doi.org/10.1057/9780230348202_2

[14] Walras, L. (1926) Eléments d'Economie Politique Pure. In: Corbaz, L., Ed., Elements of Pure Economics: Lusanne, Translated from the Edition of 1926 by W. Jaffé as Elements of Pure Economics, Richard D. Irwin, London.

[15] Arrow, K.J. and Debreu, G. (1954) Existence of an Equilibrium for a Competitive Economy. Econometrica, 22, 265-290. https://doi.org/10.2307/1907353

[16] McKenzie, L.W. (1954) On Equilibrium in Graham's Model of World Trade and Other Competitive Systems. Econometrica, 22, 147-161. https://doi.org/10.2307/1907539

[17] Clapham, J.H. (1922) Of Empty Economic Boxes. The Economic Journal, 32, 305314.

[18] Cobb, C.W. and Douglas, P.H. (1928) A Theory of Production. The American Economic Review, 18, 139-165.

[19] Fullerton, D. and Ta, C.L. (2016) Public Finance in a Nutshell: Cobb-Douglass Teaching Tool for General Equilibrium Tax Incidence and Excess Burden. CECIFO Working Paper, 1-17.

[20] Allen, R.G.D. (1938) Mathematical Analysis for Economists. Macmillan and Co., Limited, London.

[21] Basmann, R.L. (1975) Modern Logic and the Suppositious Weakness of the Empirical Foundations of Economic Science. Swiss Journal of Economics and Statistics, 111, 153-176.

[22] Jensen, B.S. (2012) Comparative Cost and Factor Endowments: Ricardo and Ohlin. In: Kemp, M.C., Nakagawa, H. and Uchida, T., Eds., Positive and Normative Analysis in International Economics, Essays in Honour of Hiroshi Ohta, Palgrave Macmillan, Basingstoke, Chapter 4, 54-83.

[23] Uzawa, H. (1961) On a Two-Sector Model of Eocnomic Growth I. Review of Economic Studies, 29, 40-47. https://doi.org/10.2307/2296180

[24] Uzawa, H. (1963) On a Two-Sector Model of Eocnomic Growth II. Review of Economic Studies, 30, 105-118. https://doi.org/10.2307/2295808

[25] Varian, H.R. (1992) Microeconomic Analysis. 3rd Edition, W. W. Norton \& Company, New York.

[26] Oniki, H. and Uzawa, H. (1965) Patterns of Trade and Investment in a Dynamic Model of International Trade. Review of Economic Studies, 32, 15-38. https://doi.org/10.2307/2296328 


\section{Appendix}

\section{Economic Analytical Relations behind Table $1 \&$ Table 2}

Table 1. The seminal studies on two-sector models (as in Table 1) are Uzawa [23] [24]. Stated briefly, the key to derive analytic solutions for all the endogenous variables is to get explicitly the general equilibrium relation between the factor endowment ratio, $K / L=k$, and wage-rental ratio $(w / r)$ : $k=\Psi(w / r)$, cf. Jensen [[11], p. 63].

Thus we must here obtain the autarky GE function $\Psi$ and its inverse $\Psi^{-1}$ :

$$
k_{j}=K_{j} / L_{j}=\Psi_{j}\left(w_{j} / r_{j}\right), \quad w_{j} / r_{j}=\Psi_{j}^{-1}\left(k_{j}\right) ; j=b, n
$$

With CD two-sector technologies and CD consumer preferences, the Walrasian general equilibrium (27) becomes, see Jensen [[11], p. 69; equation 74], Jensen [[22], p. 73; equation 79],

$$
k=\Psi(w / r)=\frac{a_{2}-\alpha_{j}\left(a_{2}-a_{1}\right)}{1-a_{2}+\alpha_{j}\left(a_{2}-a_{1}\right)} \cdot(w / r) ; \quad j=b, n
$$

Our special CD parameter assumptions-sector $N=\operatorname{sector} 1$, sector $B=$ sector 2-were:

$$
a_{1}=\alpha ; 1-a_{1}=1-\alpha ; a_{2}=1-\alpha ; 1-a_{2}=\alpha ; \alpha_{n}=\alpha ; \alpha_{b}=1-\alpha
$$

Inserting (29) into (28), we get the basic GE formulas for our two autarky economies $(\mathrm{n}, \mathrm{b})$ :

$$
\begin{gathered}
k_{n}=\Psi_{n}\left(w_{n} / r_{n}\right)=\frac{1-2 \alpha(1-\alpha)}{2 \alpha(1-\alpha)} \cdot\left(w_{n} / r_{n}\right) \\
w_{n} / r_{n}=\Psi_{n}^{-1}\left(k_{n}=1\right)=\frac{2 \alpha(1-\alpha)}{1-2 \alpha(1-\alpha)} \\
k_{b}=\Psi_{b}\left(w_{b} / r_{b}\right)=\frac{2 \alpha(1-\alpha)}{1-2 \alpha(1-\alpha)} \cdot\left(w_{b} / r_{b}\right) \\
w_{b} / r_{b}=\Psi_{b}^{-1}\left(k_{b}=1\right)=\frac{1-2 \alpha(1-\alpha)}{2 \alpha(1-\alpha)}
\end{gathered}
$$

Relative factor price expressions (31) and (33) are seen in Table 1, line 7 and Figure 6.

The CD relative commodity price (unit-cost) functions in our two-sector economies are given by, cf. Jensen [[22], p. 59; equation (14)], Varian [[25], p. 55]:

$$
\frac{p_{1}}{p_{2}}=\frac{\gamma_{2} a_{2}^{a_{2}}\left(1-a_{2}\right)^{1-a_{2}}}{\gamma_{1} a_{1}^{a_{1}}\left(1-a_{1}\right)^{1-a_{1}}}\left[\frac{w}{r}\right]^{a_{2}-a_{1}} ; \frac{p_{B}}{p_{N}}=\frac{p_{2}}{p_{1}}=\left[\frac{p_{1}}{p_{2}}\right]^{-1} ;(w / r) \in[0, \infty)
$$

With $\gamma_{1}=\gamma_{2}=1$ and using (29), the relative price formulas (34) are easily seen to become,

$$
\frac{p_{1}}{p_{2}}=(w / r)^{1-2 \alpha} ; \quad \frac{p_{B}}{p_{N}}=\left(w_{j} / r_{j}\right)^{-1(1-2 \alpha)} ; j=b, n
$$

By relative factor prices (31) and (33) and the relative price (cost) expression (35), we get: 


$$
\begin{aligned}
& \frac{p_{B n}}{p_{N n}}=\left(w_{n} / r_{n}\right)^{-1(1-2 \alpha)}=\left[\frac{1-2 \alpha(1-\alpha)}{2 \alpha(1-\alpha)}\right]^{1-2 \alpha} \\
& \frac{p_{B b}}{p_{N b}}=\left(w_{b} / r_{b}\right)^{-1(1-2 \alpha)}=\left[\frac{2 \alpha(1-\alpha)}{1-2 \alpha(1-\alpha)}\right]^{1-2 \alpha}
\end{aligned}
$$

The relative commodity price expressions (36) and (37) are seen in Table 1, line 8.

By the Equations ((9), (10)) of section 2.2, and wage-rental expressions (31), (33), we get,

$$
\begin{aligned}
& k_{N n}=\frac{\alpha}{1-\alpha} \cdot \frac{w_{n}}{r_{n}}=\frac{\alpha}{1-\alpha} \cdot \frac{2 \alpha(1-\alpha)}{1-2 \alpha(1-\alpha)}=\frac{2 \alpha^{2}}{1-2 \alpha(1-\alpha)} \\
& k_{B n}=\frac{1-\alpha}{\alpha} \cdot \frac{w_{n}}{r_{n}}=\frac{1-\alpha}{\alpha} \cdot \frac{2 \alpha(1-\alpha)}{1-2 \alpha(1-\alpha)}=\frac{2(1-\alpha)^{2}}{1-2 \alpha(1-\alpha)} \\
& k_{N b}=\frac{\alpha}{1-\alpha} \cdot \frac{w_{b}}{r_{b}}=\frac{\alpha}{1-\alpha} \cdot \frac{1-2 \alpha(1-\alpha)}{2 \alpha(1-\alpha)}=\frac{1-2 \alpha(1-\alpha)}{2(1-\alpha)^{2}} \\
& k_{B b}=\frac{1-\alpha}{\alpha} \cdot \frac{w_{b}}{r_{b}}=\frac{1-\alpha}{\alpha} \cdot \frac{1-2 \alpha(1-\alpha)}{2 \alpha(1-\alpha)}=\frac{1-2 \alpha(1-\alpha)}{2 \alpha^{2}}
\end{aligned}
$$

The GE sectoral capital-labor ratios, (38-41) are implied by the lines (1-4) in Table 1.

The fractions of labor (capital) of country (j) employed in sector 1 are given by, cf. Jensen [[11], p. 68; equation 72], and Jensen [[22], p. 73; equation 78],

$$
\frac{L_{1 j}}{L_{j}}=\frac{\alpha_{j}\left(1-a_{1}\right)}{1-a_{2}+\alpha_{j}\left(a_{2}-a_{1}\right)}, \frac{L_{2 j}}{L_{j}}=1-\frac{L_{1 j}}{L_{j}} ; \quad \frac{K_{1 j}}{K_{j}}=\frac{\alpha_{j} a_{1}}{a_{2}-\alpha_{j}\left(a_{2}-a_{1}\right)}
$$

Inserting (29) into (42) gives sector fractions of labor (capital) for autarky economies $(\mathrm{n}, \mathrm{b})$ :

$$
\begin{gathered}
\frac{L_{N n}}{L_{n}}=\frac{1}{2}=\frac{L_{B n}}{L_{n}} ; \quad \frac{K_{N n}}{K_{n}}=\frac{\alpha^{2}}{1-2 \alpha(1-\alpha)} \\
\frac{L_{N b}}{L_{b}}=\frac{(1-\alpha)^{2}}{1-2 \alpha(1-\alpha)}, \frac{L_{B b}}{L_{b}}=1-\frac{L_{N b}}{L_{b}} ; \quad \frac{K_{N b}}{K_{b}}=\frac{1}{2}=\frac{K_{B b}}{K_{b}}
\end{gathered}
$$

which appear in the lines (1-4) of Table 1 . The equations (1-2), (11-12) of section 2.2, and factor ratios (38-41), fractions (43-44), give the autarky outputs in countries $(\mathrm{n}, \mathrm{b})$ :

$$
\begin{aligned}
& N_{n}=L_{N n} k_{N n}^{\alpha}=\frac{1}{2^{1-\alpha}}\left[\frac{\alpha^{2}}{1-2 \alpha(1-\alpha)}\right]^{\alpha}, N_{b}=L_{N b} k_{N b}^{\alpha}=\frac{1}{2^{\alpha}}\left[\frac{(1-\alpha)^{2}}{1-2 \alpha(1-\alpha)}\right]^{\alpha} \\
& B_{n}=L_{B n} k_{B n}^{1-\alpha}=\frac{1}{2^{\alpha}}\left[\frac{(1-\alpha)^{2}}{1-2 \alpha(1-\alpha)}\right]^{1-\alpha}, B_{b}=L_{B b} k_{B b}^{1-\alpha}=\frac{1}{2^{1-\alpha}}\left[\frac{\alpha^{2}}{1-2 \alpha(1-\alpha)}\right]^{\alpha}
\end{aligned}
$$

which are seen in lines (5-6) of Table 1. Obtaining the distribution of these outputs among the consumers in lines (9-12) are safely left to our alert readers. 
Table 2. The seminal study of $2 \times 2 \times 2$ trade models is Oniki and Uzawa [26]. However, they only offered qualitative relations and results. Parametric closed form expressions, as in Table 2, are not available anywhere. On the background of Table 1 and the analytic expressions in this Appendix, we briefly outline how formulas in Table 2 are obtained.

We have assumed free trade between our two countries, $j=b, n$. Thus by absence of frictions of trade, the law of one commodity price, and hence one relative price $(p)$ apply:

$$
p_{B j}=p_{B}, p_{N j}=p_{N}, j=b, n: p_{b}=p_{B} / p_{N}=p_{n}=p
$$

Country trades are here always balanced, and world market equilibrium implies:

$$
X_{B j}=B_{j}-Q_{B j}=-X_{B n}=-\left(B_{n}-Q_{B n}\right)
$$

where $X_{B j}$ are exports (imports $=-X_{B j}$ ) of $\operatorname{good} B$ by country $(j) ; Q_{B j}$ is domestic demand (absorption) of good $B$ by country $(j)$. The relative price $p$, (47), (world market equilibrium terms of trade) is derived by solving the trade balance ("reciprocal demand, offer-curves") equation, (48)-reflecting specific forms of production and utility functions in both countries. With parameters (29) and $k_{b}=k_{n}=1$, it can be proved, cf. (54), that

$$
p_{b}=p_{B} / p_{N}=p_{n}=p=1
$$

Then by (49) and (35), we get wage-rental ratios, and next capital-labor ratios by $(38-41)$ :

$$
w_{b} / r_{b}=w_{n} / r_{n}=1 ; \quad k_{N n}=\frac{\alpha}{1-\alpha}, k_{B n}=\frac{1-\alpha}{\alpha}, k_{N b}=\frac{\alpha}{1-\alpha}, k_{B b}=\frac{1-\alpha}{\alpha}
$$

With $L_{N n} / L_{n}=L_{N b} / L_{b}=1-\alpha$, same technologies and factor prices imply same outputs:

$$
\begin{gathered}
N_{n}=L_{N n} k_{N n}^{\alpha}=(1-\alpha)\left[\frac{\alpha}{1-\alpha}\right]^{\alpha}=\alpha^{\alpha}(1-\alpha)^{1-\alpha}=L_{N b} k_{N b}^{\alpha}=N_{b} \\
B_{n}=L_{B n} k_{B n}^{1-\alpha}=\alpha\left[\frac{1-\alpha}{\alpha}\right]^{1-\alpha}=\alpha^{\alpha}(1-\alpha)^{1-\alpha}=L_{B b} k_{B b}^{1-\alpha}=B_{b}
\end{gathered}
$$

Remark. For parameter set (29), relative prices (49) are replaced (not proved here) by,

$$
\begin{gathered}
p=p_{B} / p_{N}=\left[2 \alpha(1-\alpha) k_{b}+[1-2 \alpha(1-\alpha)] k_{n}\right]^{2 \alpha-1}=\Phi\left(k_{b}, k_{n}\right) \\
k_{b}=k_{n}=\bar{k}: p=p_{B} / p_{N}=\bar{k}^{2 \alpha-1} ; \quad \bar{k}=1: p=p_{B} / p_{N}=1
\end{gathered}
$$

Thus (49) [independent of $\alpha$ ] -with $\alpha$-expressions (50-52), seen in Table 2is an extreme (simplest) version of terms of trade (53-54) in $2 \times 2 \times 2$ GE models with CD parameters (29). 
Submit or recommend next manuscript to SCIRP and we will provide best service for you:

Accepting pre-submission inquiries through Email, Facebook, LinkedIn, Twitter, etc. A wide selection of journals (inclusive of 9 subjects, more than 200 journals)

Providing 24-hour high-quality service

User-friendly online submission system

Fair and swift peer-review system

Efficient typesetting and proofreading procedure

Display of the result of downloads and visits, as well as the number of cited articles Maximum dissemination of your research work

Submit your manuscript at: http://papersubmission.scirp.org/

Or contact me@scirp.org 